\title{
RESPONSE OF GROWING JAPANESE QUAIL TO DIFFERENT LEVELS OF MORINGA LEAVES MEAL
}

\author{
S. A. Abd EL-Latif, A. M. Tosson, Kawsar A. Ghally and Gehad K. Mohamed \\ Department of Animal Production, Faculty of Agriculture, Minia University, Minia, Egyp
}

A total number of 300 Japanese quail (Coturnixcoturnix japanica) chicks at hatch. The quail chicks were housed in cages at hatch up to 42 days of age. The experiment aimed to study the response of growing Japanese quail to different levels of Moringa leaves meal (MLM). Quail chicks were divided randomly into three equal experimental treatments (75 in each treatment) and randomly divided into 3 equal replicates ( 25 chicks / replicate).The first treatment was fed the basal diet as a control, while the other three treatments were fed the basal diet supplemented with Moringa leaves meal (as medicinal plants), at levels of $0.20,0.40$ or $0.60 \%$, respectively. The results obtained could be summarized as follows:- Body weight and body gain of quail chicks fed dietary MLM at all levels were numerically improved $(\mathrm{P}<0.05)$ compared with the control diet during all experimental periods. The greatest numerically body gain was recorded for birds fed MLM at $0.04 \%$ compared with other diets. Adding MLM to Japanese quail diet significantly improved feed intake at all experimental periods, except from 0 to 2 weeks of age. During the whole experimental period ( 0 to 6 weeks of age), birds fed dietary MLM at levels of 0.2 or $0.4 \%$ recorded the best $(\mathrm{P}>0.01)$ feed intake compared with other dietary treatments. Feed conversion ratio of birds did not affect $(\mathrm{P}<0.05)$ as a result of adding dietary MLM at all levels to Japanese quail diet during all experimental periods, except from 2 to 4 weeks of age. Dressing percentage was numerically improved for birds fed dietary MLM at all levels compared with the control diet. Using dietary MLM at all levels did not significantly affect on the digestibility of all nutrient.

Keywords: Japanese quail, Moringa leaves meal, response of growing 